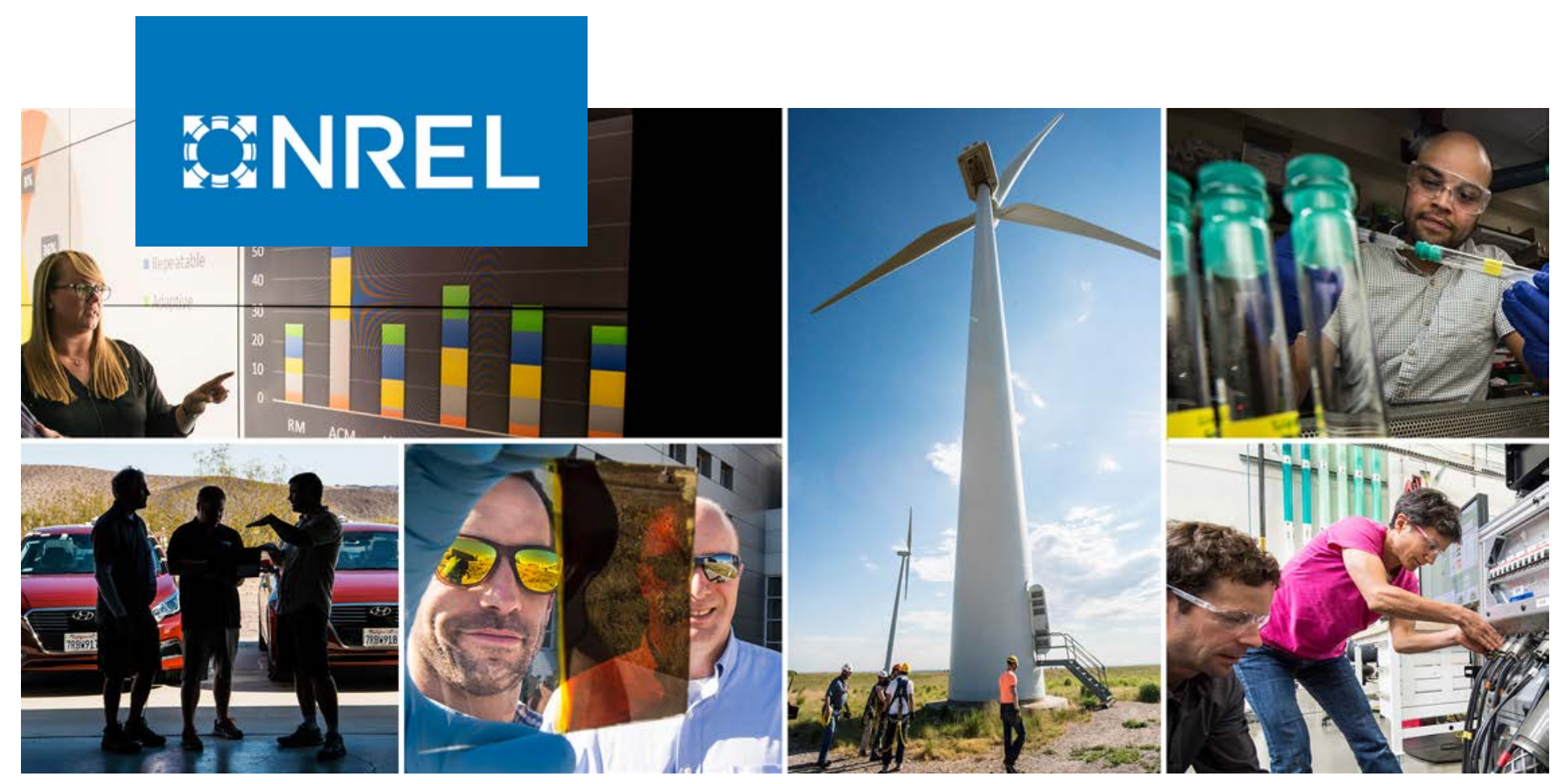

\title{
Integration of Large-Scale Renewable Energy in the Bulk Power System: Good Practices from International Experiences
}

Sadie Cox and Kaifeng Xu

National Renewable Energy Laboratory

NREL is a national laboratory of the U.S. Department of Energy Office of Energy Efficiency \& Renewable Energy

Operated by the Alliance for Sustainable Energy, LLC

This report is available at no cost from the National Renewable Energy Laboratory (NREL) at www.nrel.gov/publications.
Technical Report

NREL/TP-6A20-74445

March 2020 


\section{GNREL}

\section{Integration of Large-Scale Renewable Energy in the Bulk Power System: Good Practices from International Experiences}

Sadie Cox and Kaifeng Xu

National Renewable Energy Laboratory

\section{Suggested Citation}

Cox, Sadie and Kaifeng Xu. 2020. Integration of Large-Scale Renewable Energy in the Bulk Power System: Good Practices from International Experiences. Golden, CO: National Renewable Energy Laboratory. NREL/TP-6A20-74445.

https://www.nrel.gov/docs/fy20osti/74445.pdf.

NREL is a national laboratory of the U.S. Department of Energy Office of Energy Efficiency \& Renewable Energy Operated by the Alliance for Sustainable Energy, LLC

This report is available at no cost from the National Renewable Energy Laboratory (NREL) at www.nrel.gov/publications.

Contract No. DE-AC36-08GO28308
Technical Report NREL/TP-6A20-74445 March 2020

National Renewable Energy Laboratory 15013 Denver West Parkway Golden, CO 80401

303-275-3000 • www.nrel.gov 


\section{NOTICE}

This work was authored by the National Renewable Energy Laboratory, operated by Alliance for Sustainable Energy, LLC, for the U.S. Department of Energy (DOE) under Contract No. DE-AC36-08GO28308. Funding provided by The Children's Investment Fund Foundation (CIFF). The views expressed herein do not necessarily represent the views of the DOE or the U.S. Government.

This report is available at no cost from the National Renewable Energy Laboratory (NREL) at www.nrel.gov/publications.

U.S. Department of Energy (DOE) reports produced after 1991 and a growing number of pre-1991 documents are available free via www.OSTI.gov.

Cover Photos by Dennis Schroeder: (clockwise, left to right) NREL 51934, NREL 45897, NREL 42160, NREL 45891, NREL 48097, NREL 46526.

NREL prints on paper that contains recycled content. 


\section{Acknowledgments}

The authors would like to thank the following individuals and organizations for their thoughtful review of this work: Dan Bilello (National Renewable Energy Laboratory [NREL]), Kristen Ardani (NREL), Jeffrey Logan (NREL), Ella Zhou (NREL), Patricia Statwick (NREL), and Qin Wang (China Electric Power Research Institute). This work is supported by the Children's Investment Fund Foundation. 


\section{Table of Contents}

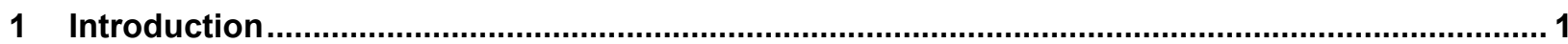

2 International Good Practices to Support Integration of Large-Scale Renewable Energy in the

Bulk Power System .......................................................................................................................

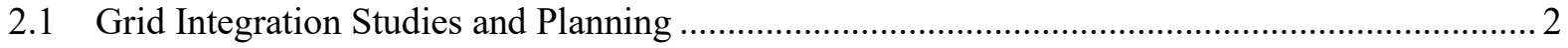

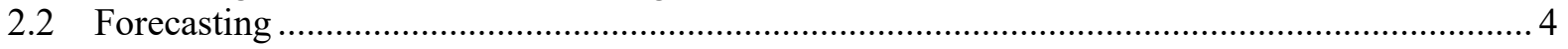

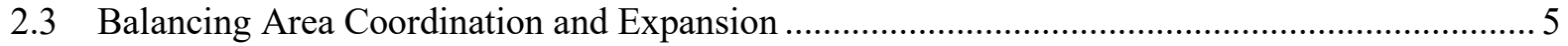

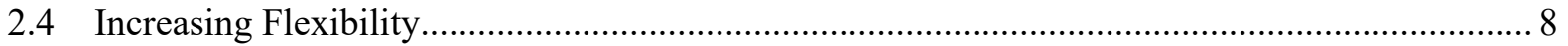

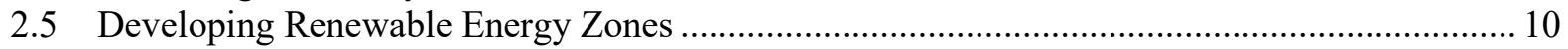

2.6 Active Power Control from Large-Scale Wind and Solar....................................................... 13

3 Case Study of Grid Integration in India: Key Actions and Impacts of Large-Scale RE Integration Options

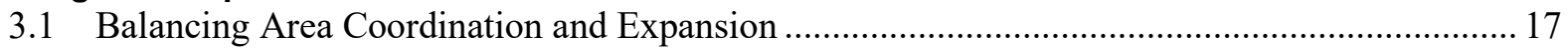

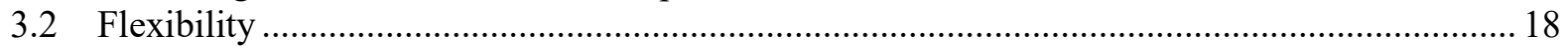

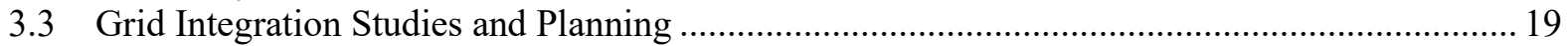

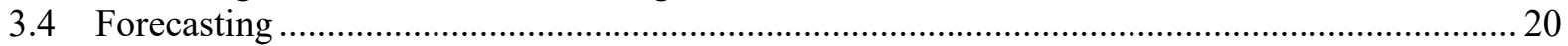

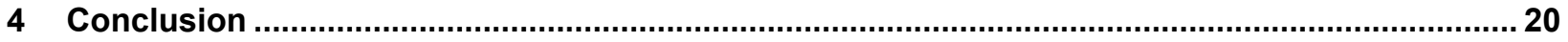

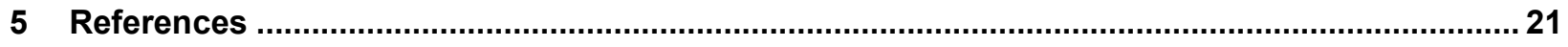




\section{List of Figures}

Figure 1. Grid integration planning decisions considering VRE impacts ......................................... 3

Figure 2. Example of wind forecast from Xcel Energy in the United States ...................................... 5

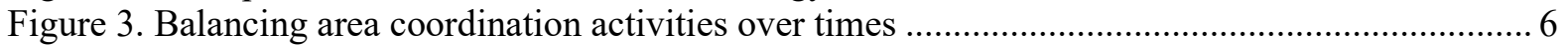

Figure 4. Potential benefits of combined balancing area operations ................................................... 7

Figure 5. Energy imbalance market and avoided curtailment ........................................................ 8

Figure 6. Examples of options for increasing flexibility in power systems with high penetrations

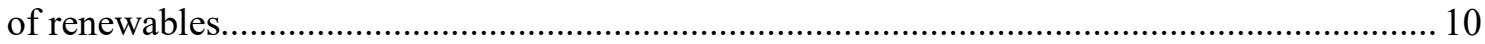

Figure 7. RE Data Explorer visualization to inform the REZ transmission planning process ............. 12

Figure 8. Renewable energy zone transmission planning process .................................................. 13

Figure 9. Frequency trace following a large contingency event..................................................... 14

Figure 10. Frequency response of the U.S. Eastern Interconnection (EI) after a generation trip event

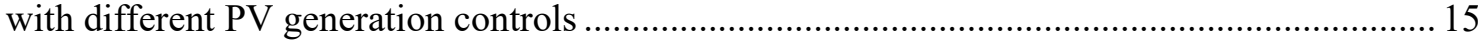

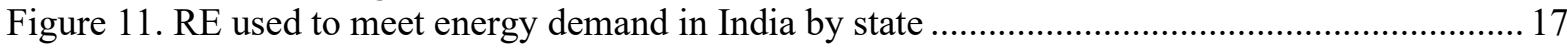

Figure 12. Actions to enable large-scale RE integration in India..................................................... 18

\section{List of Tables}

Table 1. Three Categories of Grid Integration Studies and Examples

\section{List of Text Boxes}

Text Box 1. Summary of India Case Study Findings ................................................................... 16

Text Box 2. Key Actions to Support Balancing Area Coordination and Expansion............................ 18

Text Box 3. Key Actions to Support Flexibility. 


\section{Introduction}

Deployment of increasing amounts of renewable energy (RE) presents certain grid integration challenges for the bulk power system. Bulk power typically refers to large-scale power generation at a centralized facility and in the context of RE can include wind farms, utility-scale solar, geothermal, hydro, and biomass facilities. Such generation usually occurs far from end users and requires connection to high voltage transmission. ${ }^{1}$ Centralized generation or bulk power is a critical component of many power systems and often plays a key role in balancing demand and supply, and in supporting grid stability.

Internationally, several actions and related good practices have emerged to support RE integration in the bulk power system. This report provides (1) a review of emerging international good practices that support integration of large-scale RE, (2) examples of country and jurisdiction level efforts in implementing these practices, and (3) and key considerations for any country pursuing bulk power sector transformation. Section 2 examines these actions and good practices. Section 3 provides a case study of a grid integration analysis in India and outcomes of that analysis that will inform decisions related to the bulk power system.

\footnotetext{
1 "Centralized Generation of Electricity and Its Impacts on the Environment," U.S. Environmental Protection Agency. Updated March 13, 2018. Accessed May 30, 2019: https://www.epa.gov/energy/centralized-generationelectricity-and-its-impacts-environment.
} 


\section{International Good Practices to Support Integration of Large-Scale Renewable Energy in the Bulk Power System}

Several good practices have emerged that support large-scale RE grid integration around the world. Many of these good practices have emerged through an initiative of the United States Agency for International Development (USAID) called Greening the Grid. ${ }^{2}$ This section seeks to summarize many lessons from that work that are specific to the bulk power system. Good practices covered in this section align with the following action areas: grid integration studies and planning, forecasting, balancing area coordination and expansion, increasing flexibility, developing RE zones, and active power control for large-scale wind and solar.

\subsection{Grid Integration Studies and Planning}

Grid integration studies and planning processes encompass analysis of various power sector scenarios and sensitivities, identification of key actions, and engagement of stakeholders to support integration of variable renewable energy (VRE) (Katz and Cochran 2015).

Without effective integration methods, increasing renewable penetration, along with transmission and capacity expansion can present challenges for an energy system's stability and reliability. Therefore robust grid integration studies are critical for efficiently planning for increasing amounts of variable, renewable energy. A grid integration study has four general steps: (1) data collection, (2) scenario development, (3) power system modeling, and (4) final analysis and report development.

$\mathrm{RE}$ targets can frame scenarios to be modeled and analyzed in grid integration studies, and the results can be used to identify the pathways and barriers to achieving the targets. Grid integration studies can identify the system flexibility requirements for wind and solar integration, and they can increase stakeholder confidence in the utility decision making process.

Meanwhile, energy system planning is critical to providing reliable and economic operation of the power system. Unlike traditional approaches for power system planning, which may include power demand projections, generation mix planning, and designing the transmission system, renewable integration adds a degree of complexity that is due to increased variability and uncertainty associated with wind and solar resources. Therefore, grid integration planning for VRE needs to consider the generation output variability and the potential impacts to bulk power system flexibility. Figure 1 shows a planning process that takes into consideration the potential for renewable energy integration. Although this approach involves new decision processes, planning for variable renewable energy still encompasses traditional tools such as capacity expansion models and production cost models. Improved generation forecasting to address renewable energy variability risks and reduce system costs are integral aspects of effective grid integration analysis and planning, and is detailed in Section 2.2.

\footnotetext{
${ }^{2}$ See accessible at https://greeningthegrid.org.
} 


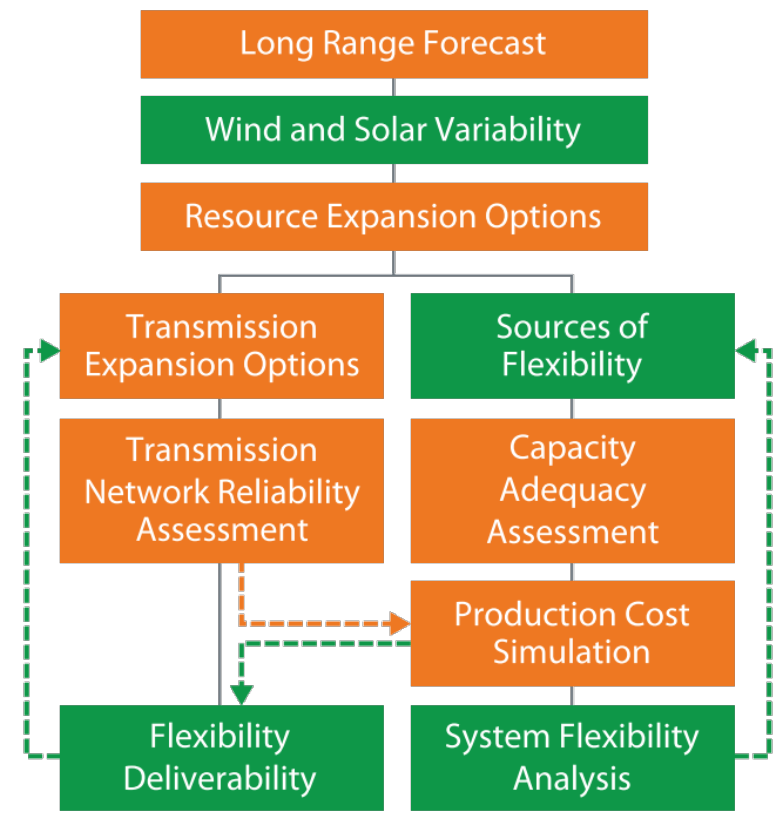

Figure 1. Grid integration planning decisions considering VRE impacts

Adapted from Milligan and Katz 2016

Traditional planning elements are presented in orange and new planning elements to support VRE integration are presented in green along with green arrows that indicate new connections between planning stages.

Depending on broader objectives and timescales, there are three general categories of grid integration studies. First, a capacity expansion study is a long-term view investigating the infrastructure needs to achieve VRE targets. Second, an electricity production cost study typically examines one future year to explore the power scheduling and dispatch impacts of VRE target scenarios. Finally, a power flow study has the shortest time frame (seconds to minutes) and is designed to test the ability of the power system to respond to disturbances. Table 1 summarizes these three categories along with examples of studies supported by the National Renewable Energy Laboratory (NREL).

Table 1. Three Categories of Grid Integration Studies and Examples

\begin{tabular}{|l|l|l|l|}
\cline { 2 - 4 } \multicolumn{1}{c|}{} & $\begin{array}{l}\text { Capacity Expansion } \\
\text { Study }\end{array}$ & $\begin{array}{l}\text { Electricity Production } \\
\text { Cost Study }\end{array}$ & Power Flow Study \\
\hline Objective & $\begin{array}{l}\text { Identify where, when, how } \\
\text { much, and what types of } \\
\text { infrastructure (generation } \\
\text { and/or transmission) would } \\
\text { achieve VRE targets at } \\
\text { least cost, considering } \\
\text { factors such as new } \\
\text { policies, technological } \\
\text { advancement, fuel prices, } \\
\text { and demand projections }\end{array}$ & $\begin{array}{l}\text { Assess the impacts of one } \\
\text { or more VRE penetration } \\
\text { scenarios on bulk power } \\
\text { scheduling and economic } \\
\text { dispatch }\end{array}$ & $\begin{array}{l}\text { Test the ability of a power } \\
\text { system to respond to a real- } \\
\text { time disturbance such as } \\
\text { an unplanned generator or } \\
\text { transmission line outage }\end{array}$ \\
\hline $\begin{array}{l}\text { Simulation } \\
\text { Horizon }\end{array}$ & $\begin{array}{l}\text { Long term (e.g., 20- } \\
\text { 50 years) }\end{array}$ & $\begin{array}{l}\text { One future year, typically } \\
\text { modeled at hourly or } \\
\text { subhourly dispatch intervals }\end{array}$ & $\begin{array}{l}\text { Seconds to minutes, } \\
\text { corresponding to periods } \\
\text { of system stress }\end{array}$ \\
\hline
\end{tabular}




\begin{tabular}{|c|c|c|c|}
\hline & $\begin{array}{l}\text { Capacity Expansion } \\
\text { Study }\end{array}$ & $\begin{array}{l}\text { Electricity Production } \\
\text { Cost Study }\end{array}$ & Power Flow Study \\
\hline $\begin{array}{l}\text { Examples } \\
\text { of Outputs }\end{array}$ & $\begin{array}{l}\text { - Cost-effective locations } \\
\text { for VRE and conventional } \\
\text { generation siting } \\
\text { - Optimal transmission } \\
\text { system upgrades and } \\
\text { expansion } \\
\text { - System-wide } \\
\text { capital costs } \\
\text { - Economic development } \\
\text { indicators associated } \\
\text { with different VRE } \\
\text { penetrations and } \\
\text { configurations }\end{array}$ & $\begin{array}{l}\text { - VRE curtailment levels } \\
\text { - Generator ramps and } \\
\text { plant load factors } \\
\text { - Reserve requirements } \\
\text { - Emissions and fuel } \\
\text { consumption } \\
\text { - Transmission constraints } \\
\text { and operational costs } \\
\text { associated with different } \\
\text { VRE scenarios and } \\
\text { flexibility options } \\
\text { - Identification of periods } \\
\text { of high stress, to inform } \\
\text { subsequent testing via } \\
\text { power flow studies }\end{array}$ & $\begin{array}{l}\text { System recovery time, } \\
\text { (i.e., magnitude and } \\
\text { duration of frequency } \\
\text { deviation following a } \\
\text { disturbance) } \\
\text { - Fault tolerance } \\
\text { - Voltage stability and } \\
\text { contingency response } \\
\text { - Mitigation strategies } \\
\text { - Reliability check for } \\
\text { production cost scenarios }\end{array}$ \\
\hline $\begin{array}{l}\text { Case } \\
\text { Study }\end{array}$ & $\begin{array}{l}\text { The Renewable Electricity } \\
\text { Futures Study analyzed the } \\
\text { extent to which RE } \\
\text { technologies commercially } \\
\text { available today could meet } \\
\text { the electricity demands of } \\
\text { the continental United } \\
\text { States through } 2050 \text {, } \\
\text { focusing on an } 80 \% \text { RE } \\
\text { generation scenario. }^{\text {a }}\end{array}$ & $\begin{array}{l}\text { India, Mexico, and the } \\
\text { Philippines are conducting } \\
\text { production cost studies to } \\
\text { evaluate different RE } \\
\text { targets and identify } \\
\text { opportunities to facilitate } \\
\text { cost-effective wind and } \\
\text { solar generation } \\
\text { (Barrows et al. 2018; } \\
\text { Palchak et al. 2017). }\end{array}$ & $\begin{array}{l}\text { The Western Wind and } \\
\text { Solar Integration Study } \\
\text { (Phase 3) used power flow } \\
\text { analysis to evaluate how } \\
\text { high penetrations of wind } \\
\text { and solar would impact } \\
\text { the transient stability and } \\
\text { frequency response of } \\
\text { the U.S. Western } \\
\text { Interconnection (Miller et } \\
\text { al. 2014). }\end{array}$ \\
\hline
\end{tabular}

Adapted from Katz and Chernyakhovskiy 2016

a "Renewable Electricity Futures Study," NREL, accessed May 30, 2019: https://www.nrel.gov/analysis/re-futures.html

Overall, grid integration studies and planning can provide three key benefits related to renewable energy deployment. First, they can enable system developers, generators, policymakers and other stakeholders to establish energy system flexibility requirements as RE penetration is increased. Second, they can support decision-makers in identifying costs associated with higher penetrations of RE and cost-effective approaches to support scale-up. Finally, these studies can enhance confidence of operators and investors to support RE goals.

\subsection{Forecasting}

Improved generation forecasting to address renewable energy variability risks and reduce system costs is essential to effective grid integration analysis and planning. Power system operators use forecasting to more efficiently balance supply and demand. Improved forecasting can both enable integration of large-scale RE in the bulk power system and support reliability of the system. Accurate and timely forecasting of wind and solar generation, and improved scheduling that is informed by forecasting, can also reduce the need for expensive reserve power, thus decreasing overall costs for the system. Because of the variability of wind and solar, forecasting is also critical to decreasing uncertainty and ensuring a reliable power system. 
System operators develop forecasts to bring together "weather observations, satellite data, numerical weather prediction models, and statistical analysis to inform estimates of the level and location of generation in the near future" (Tian and Chernyakhovskiy 2016). Key data inputs to support solar and wind forecasting include geographic location, current and historical generation output, capacity, and hub height. Figure 2 shows an example of a wind forecast for a utility in the United States.

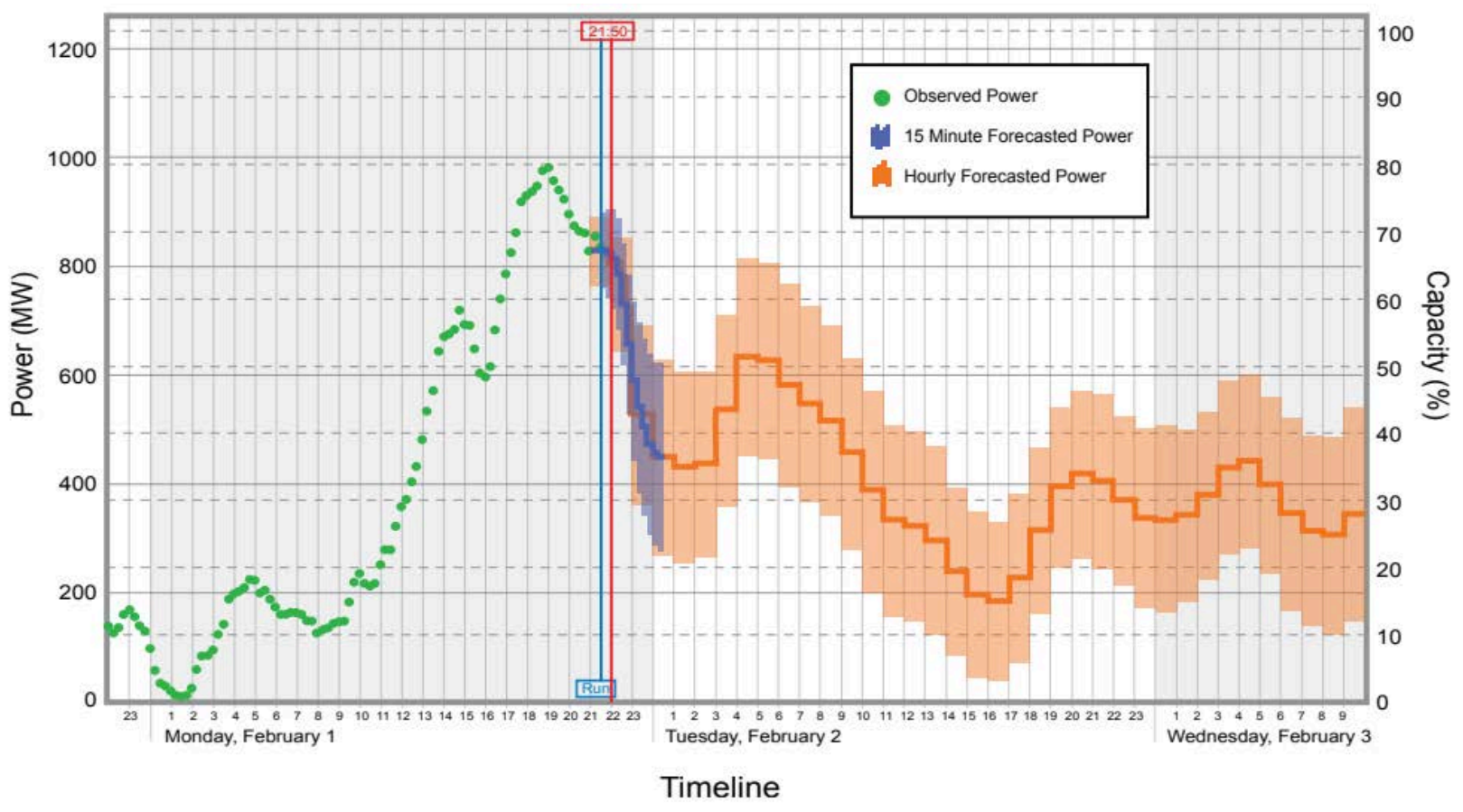

Figure 2. Example of wind forecast from Xcel Energy in the United States

Source: Tian and Chernyakhovskiy 2016

Good practices have emerged internationally to support improved forecasting. The USAID Greening the Grid program has compiled and summarized several wind and solar forecasting good practices. ${ }^{3}$

\subsection{Balancing Area Coordination and Expansion}

In a balancing area (BA), the electricity supply and demand are balanced within a defined geographic boundary. BA coordination refers to the exchange of balancing services, sharing reserves or scheduling and dispatching generation outputs between two or more BAs. Larger BAs can enable system operators in identifying the most cost-effective generator resources to dispatch, thus benefiting overall energy system operation. In addition, coordinated planning across large geographic areas and balancing areas is an important aspect of cross-border power trade approaches.

Increasing shares of renewables within a geographic area can lead to output uncertainty and variability challenges. BA coordination is a key mechanism to address this challenge. By using

\footnotetext{
${ }^{3}$ See "Forecasting," Greening the Grid, https://greeningthegrid.org/integration-in-depth/forecasting.
} 
BA coordination, the net variability is typically reduced. Based on timescale, three broad categories of cooperation at the BA operational level are illustrated in Figure 3.

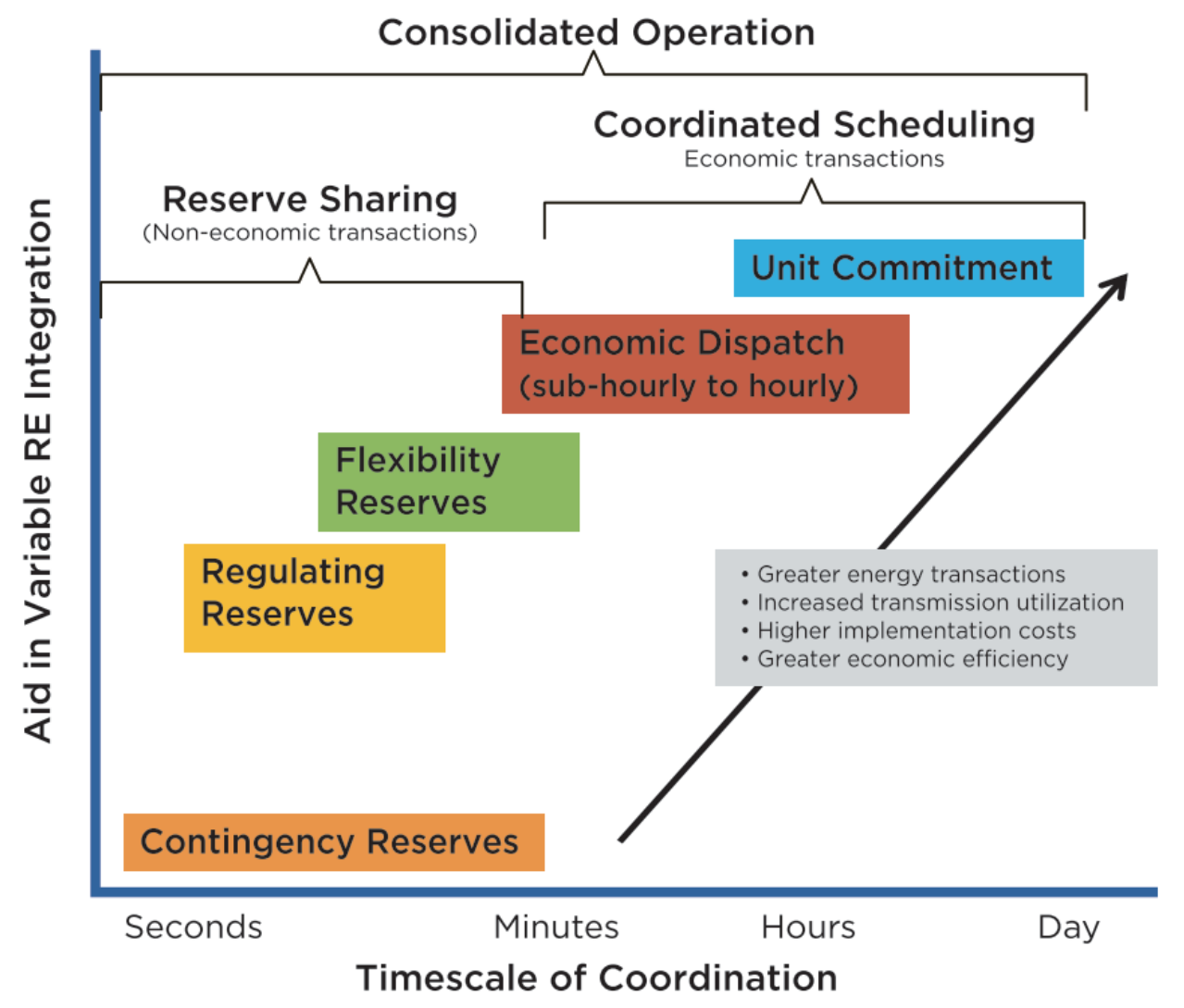

Figure 3. Balancing area coordination activities over times

Adapted from Denholm and Cochran 2015

Reserve sharing allows two or more BAs to manage reserves across their individual geographic areas. Because reserve requirements do not rise proportionally with the size of the load area, by sharing the reserves, the total reserve requirement can be less than the sum of individual BA reserve requirements. Coordinated scheduling can take place in short-term economic dispatch and longer-term unit commitment timescales. The bid-based centralized market and facilitated bilateral exchange are two potential mechanisms to implement coordinated scheduling. Consolidated operation refers to the merging of two or more balancing areas into a single operating entity. The new expanded entity can be either a vertically integrated entity or an regional transmission organization/independent system operator ${ }^{4}$ depending on the market structure. Figure 4 shows how BA coordination improves energy system flexibility and reduces system cost by decreasing ramping needs.

\footnotetext{
${ }^{4}$ In the United States, a regional transmission organization (RTO) is a power transmission system operator that coordinates, controls, and monitors the bulk power system to ensure an efficient electric grid over a large area. An independent system operator (ISO) performs similar functions but typically for an area smaller than an RTO. Nine ISO/RTOs in the United States and Canada currently manage two-thirds of the U.S. power supply ("ISO/RTO Council," https://isorto.org/).
} 


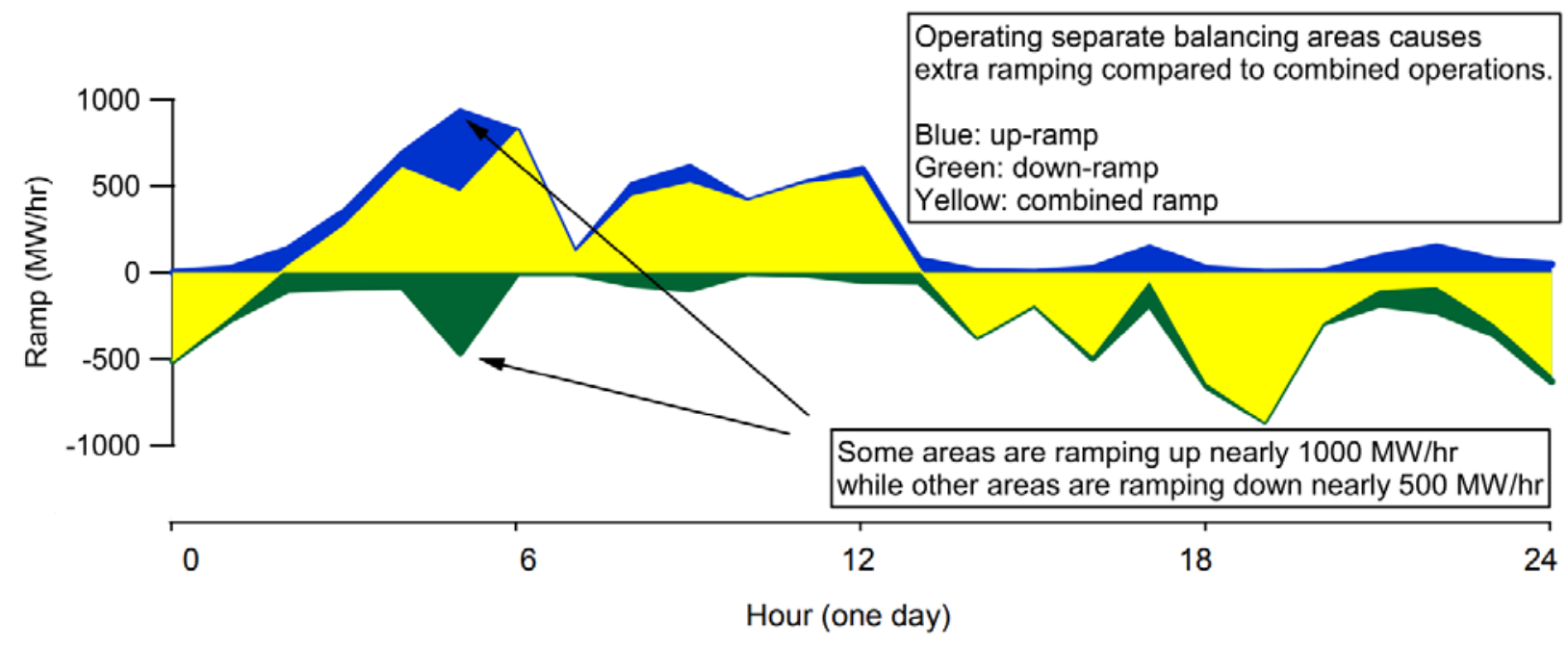

Figure 4. Potential benefits of combined balancing area operations

Adapted from Milligan and Kirby 2007

In Figure 4, the solid blue area refers to the ramping up requirements for a BA while the solid green area refers to the ramping down requirements for another BA. By implementing BA coordination, these two BAs can share reserves and exchange generation capacities, which results in the combined ramp requirements (solid yellow area); thus, the required ramping for the whole system is reduced.

California ISO's Western Energy Imbalance Market (EIM), which has been operating since 2014, provides one example of expanding regional coordination in a bid-based centralized market. ${ }^{5}$ This EIM real-time bulk power trading market now includes nine providers and eight more pending entities. ${ }^{6}$ A significant potential benefit of BA coordination and expansion is that it reduces renewable curtailment. By the end of 2018, the Western EIM market had avoided more than 700 cumulative gigawatt-hours of curtailments (Figure 5), and the total gross benefits (including cost savings and the use of surplus RE) from Western EIM since November 2014 reached \$565 million (CAISO 2019).

\footnotetext{
${ }^{5}$ The framework for restructured electricity markets in which all generators bid in costs to a centralized market operator. The generators selected for dispatch then receive a uniform clearing price based on the cost of the marginal generator.

${ }^{6}$ By June 2019, Arizona Public Service, California ISO, Balancing Authority of Northern California/SMUD, Idaho Power, NV Energy, PacificCorp, Portland General Electric, Powerex, and Puget Sound Energy were enrolled in the Western EIM. And enrollment is pending for the Salt River Project, Seattle City Light, Los Angeles Department of Water \& Power, Public Service Company of New Mexico, NorthWestern Energy, Turlock Irrigation District, Tucson Electric Power, and Avista.
} 


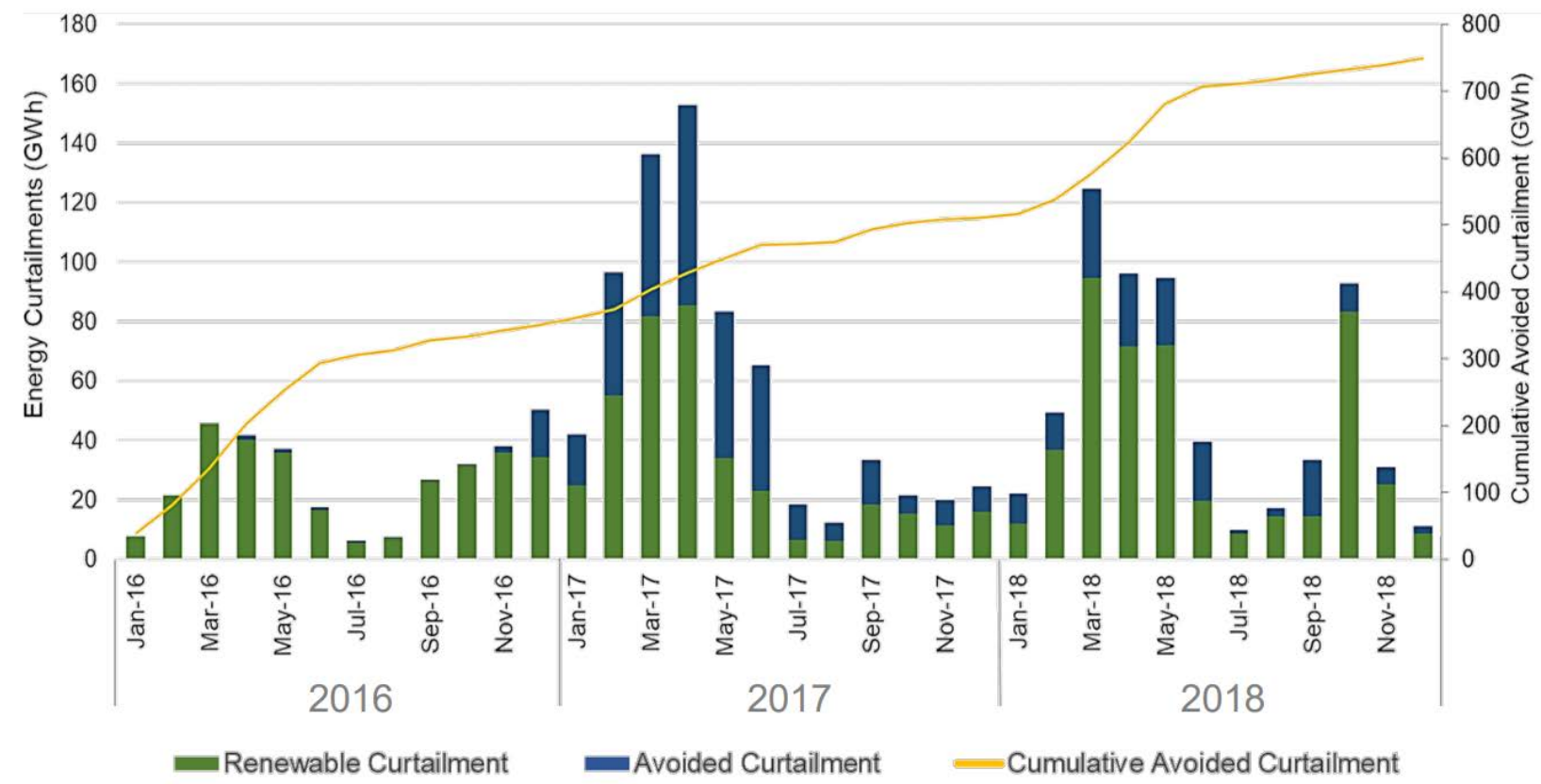

Figure 5. Energy imbalance market and avoided curtailment

Adapted from Rothleder 2019

Overall, BA coordination and expansion can support three key benefits. First, BA coordination can enable system operators in identifying and developing the most cost-effective renewable resources to dispatch through both intra-regional and interregional approaches, which can reduce the cost compared with dispatching resource in a single BA. Second, BA coordination can increase power system stability, reduce the flexibly ramping reserve, and reduce variability and uncertainty impacts of certain renewables. Finally, BA coordination can reduce renewable energy curtailment by transferring renewable outputs across larger balancing areas.

\subsection{Increasing Flexibility}

When integrating increasing amounts of large-scale RE, it is important to consider options to support operational flexibility. Operational flexibility allows a power system to respond efficiently to changes in supply and demand to ensure reliability across all timescales (IEA, CEM, and 21CPP 2019). VRE increases uncertainty in relation to power supply and thus requires greater amounts of flexibility. Benefits of flexibility may include decreased RE curtailment, less price variability, improved RE investment returns, and environmental benefits related to greater utilization of RE. Challenges associated with introducing more flexibility to a system may include greater ramping of traditional plants resulting in higher operations and maintenance costs and less revenue for some generating units because of more frequent shutdowns. The key options to support flexibility in the context of high penetrations of renewables are described in this section.

Improved Forecasting and Scheduling: As presented in Section 2.2, improved forecasting can allow system operators to better respond to changes in power supply and demand through close to real-time scheduling of asset use. Markets can thus operate more efficiently, and the need for high cost reserves can be reduced. 
Balancing Area Expansion: As presented in Section 2.3, expanding the BA and improving coordination can also support flexibility by bringing in a more diverse mix of RE resources and consumers. Section 3 describes BA expansion and coordination as a key action to supporting large-scale RE grid integration in India that can both support operational cost savings and reduce RE curtailment through improved flexibility.

Demand Response and Demand Side Management: To support flexibility, utilities or other power sector entities can use price signals to influence consumer demand for power. Actions that can support demand adjustments are time-of-use and real-time pricing for energy consumption, smart metering, and system operator automated load control mechanisms.

Storage Technologies: Storage technologies allow excess energy to be stored for use when demand for energy is higher. Storage technologies can include batteries, thermal, and pumped hydro technologies.

Flexible Generation: Dispatchable RE as well as conventional thermal plants can support flexibility. This is possible through (1) rapid ramp-up and ramp-down (and/or start-up and shutdown) capabilities responding to load and (2) efficient operation at lower minimum levels when renewable generation output is high. New plants can be designed to provide these capabilities or existing plants can be retrofitted. Distributed generation technologies can also provide flexible generation following load. However, appropriate interconnection standards and codes are needed to ensure voltage regulation is not negatively impacted by fluctuating distributed generation, such as that provided by solar photovoltaics (PV). Planning for flexible and optimized interaction and communication across the transmission (i.e., bulk power) and distribution systems is an area of increasing attention internationally. This interaction can be supported by development of shared network models across TSOs and DSOs, advanced data exchange, real time monitoring and analytics, and policy frameworks to support dispatchable DG, aggregation of DER and grid interactivity with consumer demand (e.g., through smart infrastructure and responsive equipment), among other measures (Cox et al. 2020).

In the case of India presented in Section 3, coal plant flexibility, in particular the lowering of minimum plant generation, was identified as a key source of flexibility to support large-scale RE integration goals. Lowering minimum plant generation was found to support (1) reductions in RE curtailment and (2) annual operational cost savings, when combined with BA scheduling improvements.

Dispatchable utility-scale wind and solar are also enabling flexible generation. With continuing declines in storage costs, wind-plus-storage systems can now be made available to meet a limited capacity window (Knauf 2018). Studies are also indicating that utility-scale wind and solar can help operators meet the flexibility and reliability needs of the grid by controlling power output (Gevorgian and O’Neill 2016; Nelson et al. 2018).

Flexible Transmission: Extension of intra-regional and interregional transmission lines to bring in additional balancing resources can reduce net variability and enable flexibility by aggregating generation resources. 
Policymakers can consider intervention options (highlighted above) and corresponding costs to support energy system flexibility with increasing VREs. In Figure 6, several of these options to support flexibility are compared in relation to cost.

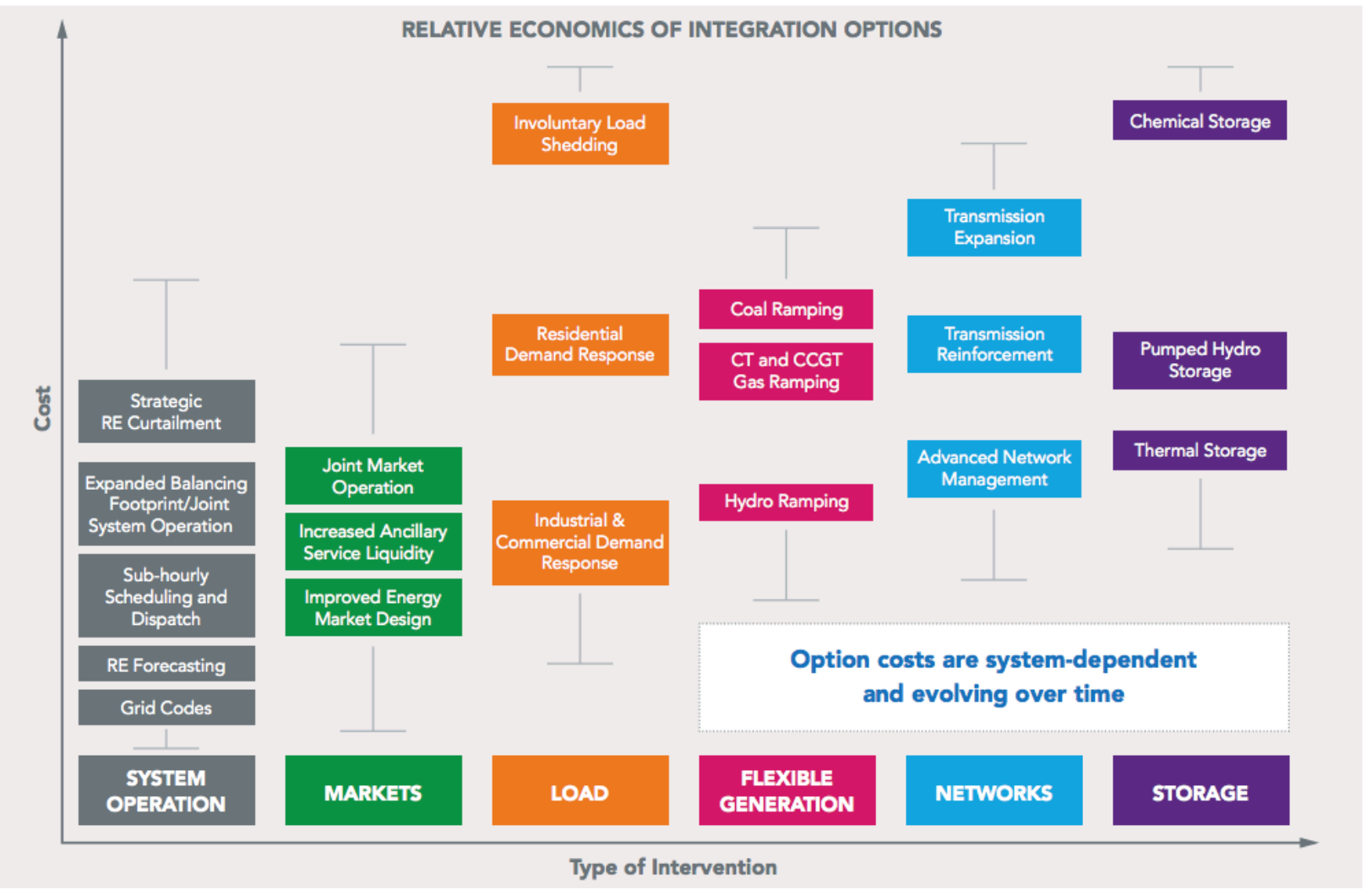

Figure 6. Examples of options for increasing flexibility in power systems with high penetrations of renewables

Source: Cochran et al. 2014

$\mathrm{CT}=$ combustion turbine, $\mathrm{CCGT}=$ combined-cycle gas turbine

\subsection{Developing Renewable Energy Zones}

RE zones (REZ) ${ }^{7}$ can be developed to advance informed planning of transmission in support of integration of large-scale renewables. Several countries and jurisdictions have developed REZs, including the state of Texas, the Philippines, and Denmark (Lee, Flores-Espino, and Hurlbut 2017). ${ }^{8}$ Because planning for, and developing, new transmission can be a very lengthy process (sometimes requiring 10 years or more), harmonizing the process with planning for RE development can help achieve RE goals more efficiently. Thus, REZs help overcome a significant barrier to RE development, which is that "wind and solar developers face difficulties securing financing without access to transmission, but before approving new transmission,

\footnotetext{
7 "REZs are geographic areas with high-quality variable renewable energy resources (such as wind and solar), suitable topography and land use designations for development, and demonstrated interest from project developers" ("Renewable Energy Zone (REZ) Toolkit," Greening the Grid, https://greeningthegrid.org/Renewable-EnergyZones-Toolkit.

${ }^{8}$ See also "Greening the Grid: Philippines," Greening the Grid, accessed May 30, 2019:

https://greeningthegrid.org/where-we-work/greening-the-grid-philippines.
} 
regulators typically need a guarantee that new lines will be used and that costs will be recoverable" (Hurlbut, Chernyakhovskiy, and Cochran 2016). REZs allow planners to support $\mathrm{RE}$ development in areas with the greatest economic potential for RE while also integrating policies and regulations to enable RE development. Stakeholders, including planners, developers, nongovernmental organizations, and others play a critical role in the REZ transmission planning process and in addressing regulatory barriers that might arise through the process.

The first step in the REZ transmission planning process involves assessing current legal and regulatory barriers to RE development that could potentially be mitigated by the REZ process. This step can include land rights and acquisition issues, social and environmental impacts associated with land use for transmission, allocation of costs for transmission, and approaches to coordinating across regulatory entities at different levels. Some of these areas also relate to the screening process to identify REZs, as described below.

After assessing the legal and regulatory environment, planners can begin to screen potential areas for RE development and transmission extension that would be most cost-effective and offer the most benefits. Such screening involves assessing RE resource quality and land, and social and environmental factors (e.g., slope or protected areas) that either support, or impede, RE development. Once these areas are identified, they can be presented in a clear visualization framework to potential investors and developers to get their input on identification of REZ. The RE Data Explorer is an example of a visualization and analysis tool that can be used for this step of the REZ transmission planning process. As an example, Figure 7 (next page) presents an RE Data Explorer analysis for Vietnam that could inform REZs. ${ }^{9}$ In some cases, developers may show clear and targeted interest by performing feasibility studies or acquiring land in certain zones based on the initial screening results. Planners can then use the information gathered through developer outreach and clear indications of interest to prioritize certain zones for transmission expansion.

Within these prioritized zones, more detailed and targeted analysis can then be performed including grid integration studies and detailed economic assessments (e.g., levelized cost of energy analysis and cost/benefit analyses). The Southeast Asia RE Data Explorer used in the analysis for Vietnam includes a levelized cost of energy analysis tool within the visualization framework that allows further assessment and information to inform the REZ transmission planning process, and this tool could be used by planners or provided to developers.

Each of the steps above will inform the final identification of REZs, which can then inform the design and implementation of transmission extension plans to integrate REZs with the greatest potential and interest from developers. Overall, this process can help to more efficiently align the planning timescales for transmission extension and RE development to allow countries to meet large-scale RE development goals in a shorter time frame. The steps of the REZ transmission planning process are presented in Figure 8.

\footnotetext{
${ }^{9}$ The RE Data Explorer for Southeast Asia can be accessed at https://maps.nrel.gov/rede-southeast-asia/, and other country tools are available at https://www.re-explorer.org/launch.html.
} 


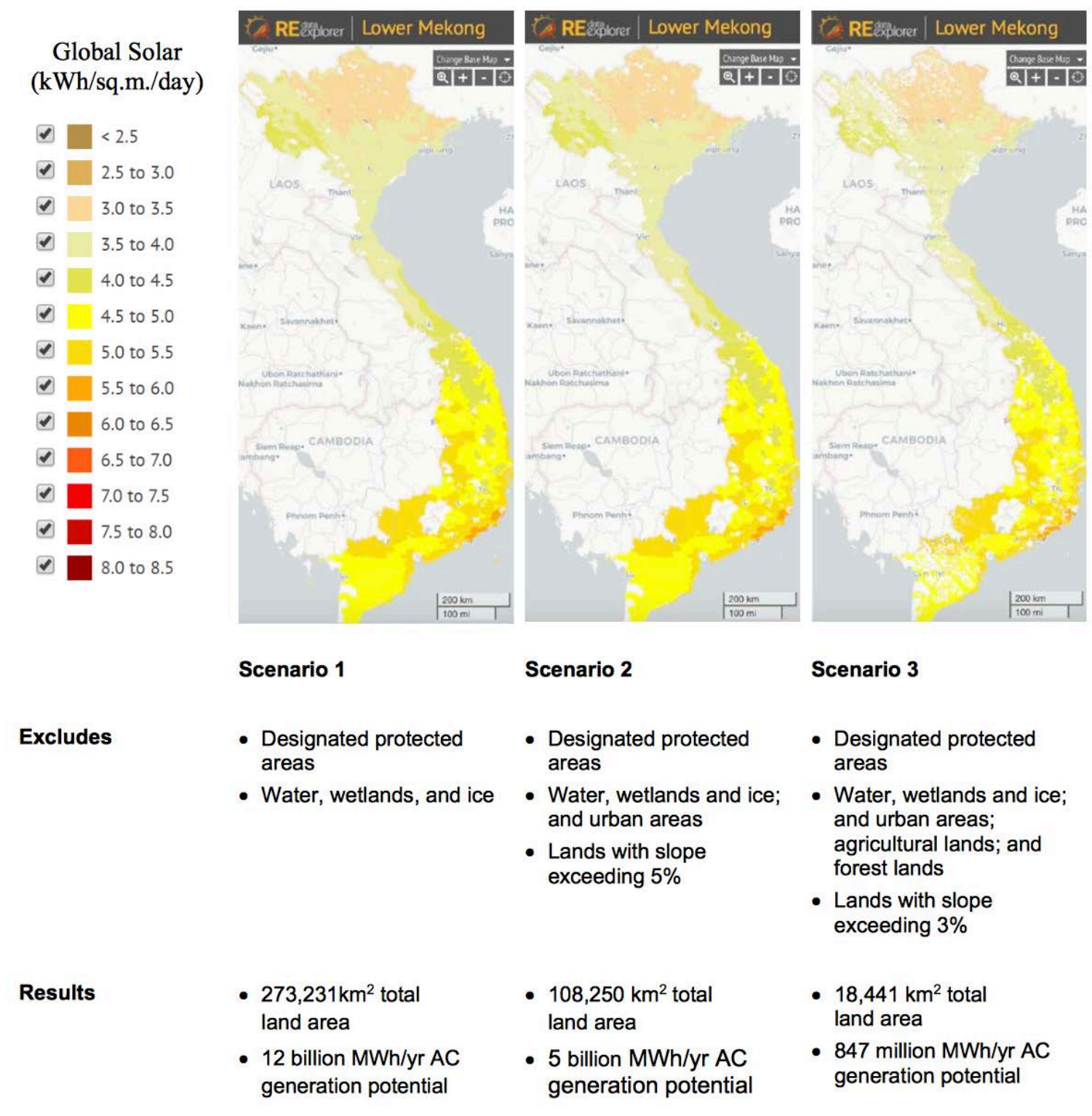

Figure 7. RE Data Explorer visualization to inform the REZ transmission planning process

The figure shows three examples of technical potential scenarios for fixed-tilt solar PV in Vietnam.

Source: RE Data Explorer 


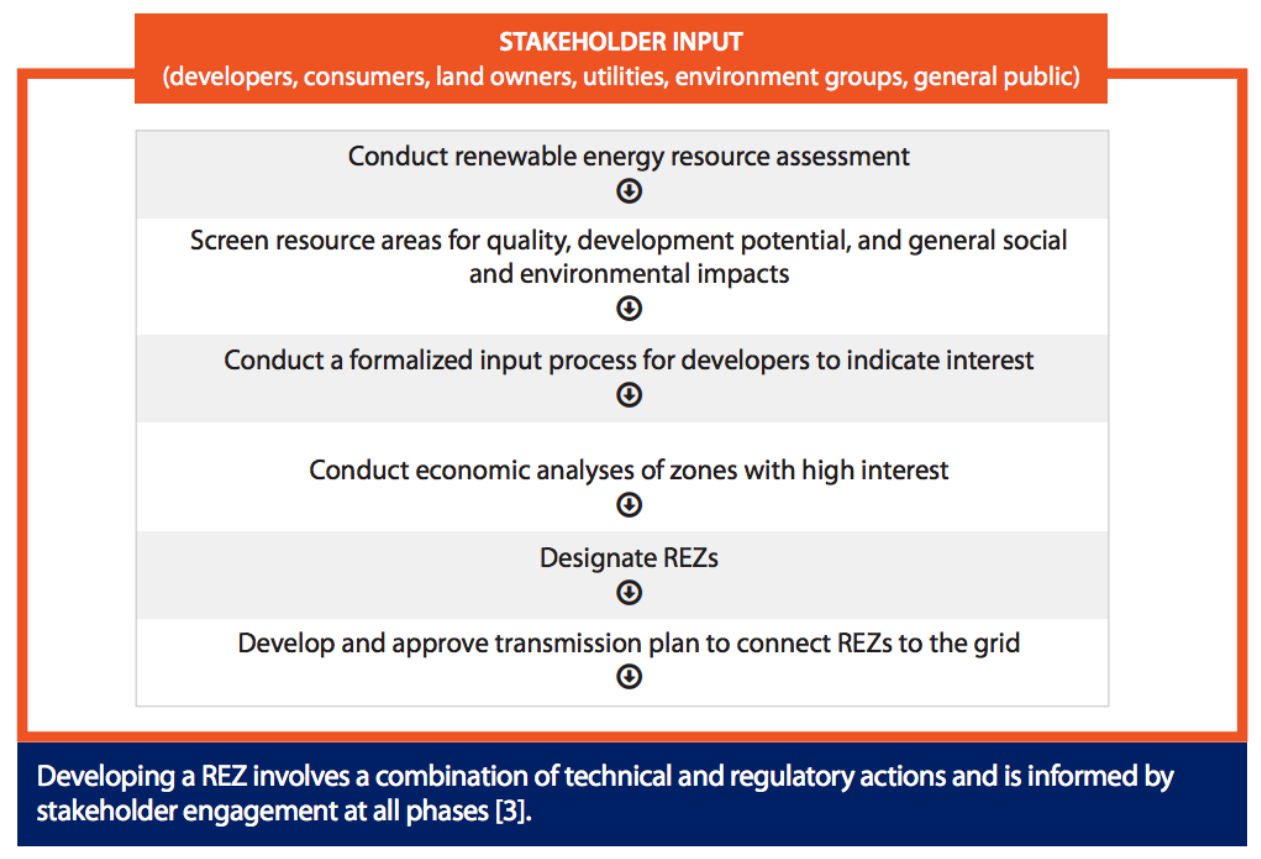

Figure 8. Renewable energy zone transmission planning process

Source: Hurlbut, Chernyakhovskiy, and Cochran 2016

\subsection{Active Power Control from Large-Scale Wind and Solar}

Active power is the power consumed in the AC circuit. Active power control (APC) services assist the energy system in times of disturbances and during normal conditions, and they support maintenance of system frequency and voltage.

APC can provide services such as inertial response, primary frequency response, secondary frequency response and ramp-rate limiting controls. Conventional power plants are often recognized as the main participants in providing these services. Variability and uncertainty of certain renewable energy sources, such as wind and solar, can present challenges to providing APC. These technologies are connected to the grid through an inverter and are nonsynchronous to the grid's frequency. However, advances in APC for bulk renewable technologies shows promise for the future.

In 2012, the North American Electric Reliability Corporation's Integration of Variable Generation Task Force proposed requirements for variable generators to provide APC capabilities like curtailment and rate limits. The task force also considered the potential opportunities of variable RE generators to provide over-frequency drop response, primary frequency response, and inertial response in the future (NERC 2014). Figure 9 shows how energy system frequency can change during a disturbance and how APC services can respond and support frequency recovery. 


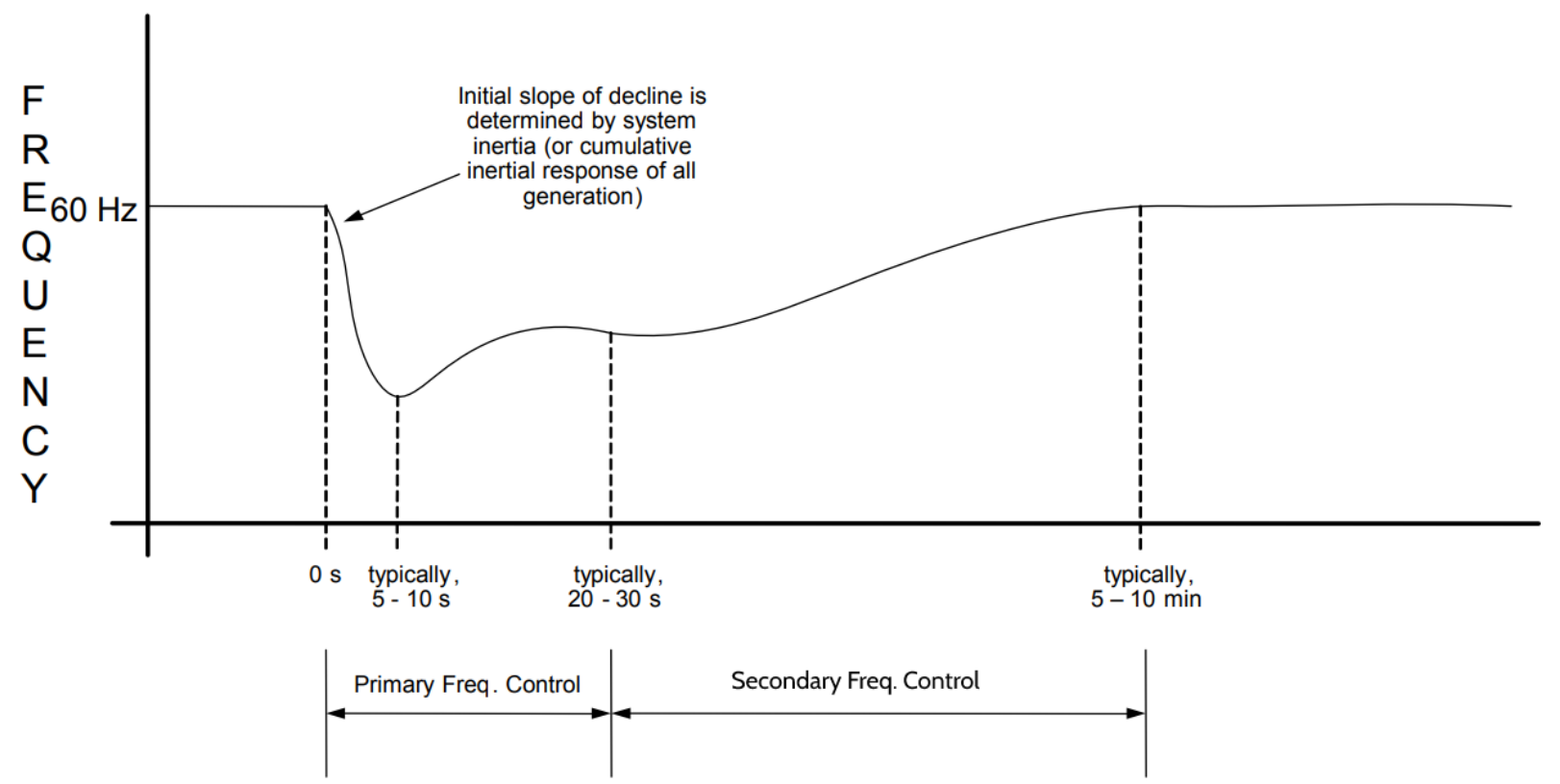

Figure 9. Frequency trace following a large contingency event

Inertial control, primary frequency control and secondary frequency control each serve a different purpose for frequency recovery

Adapted from Ela et al. 2014

Utility-scale renewable generators can provide three forms of APC services during both a contingency event ${ }^{10}$ and normal variation. An inertial control response takes place immediately after a power disturbance (loss-of-supply or loss-of-load). During a loss-of-supply event, a conventional generator will inject the kinetic energy of its rotating masses to the grid, thus slowing the initial rate of change of frequency (Ela et al. 2014; Muljadi et al. 2012). On the other hand, extracting the kinetic energy of a generator's rotating masses from the grid will take place during a loss-of-load event, which eventually speeds up the rotation and system frequency (Ela et al. 2014). Wind turbines can provide the inertial response by using energy stored in the rotating blades, as well as by capturing more energy from converters (Ela 2013). An NREL study (Muljadi et al. 2012) showed that a 1.5-MW wind turbine can release as much as 200 kilowatts from inertia during 15 seconds when the wind rotors slow by 5 revolutions per minute from the initial speed. Second, following inertial response, primary frequency response refers to the action of changing generation outputs to balance generation and load. When grid frequency increases, wind and solar generators can provide frequency response by dropping electricity outputs. When system frequency drops, generators can provide primary frequency response only when they are operating below the maximum output levels (Ela 2013). Lastly, the secondary frequency response ${ }^{11}$ is a response that is slower than primary frequency response and which can return the frequency back to normal. Generators equipped with automatic generation control (AGC) systems can change the output by responding to signals. Wind turbines can provide the secondary frequency response by pitching their blades to increase or decrease output (Ela 2013).

${ }^{10}$ A contingency event refers to the unexpected failure or outage of an energy system component.

${ }^{11}$ Secondary frequency response is also called load frequency control, regulation, and secondary control 
Solar generators face greater obstacles in providing inertial response, as the solar PV system has no rotating mechanical parts. However, solar generators can reserve and use inertia control by making PV panels work in an over-voltage condition (Liu et al. 2013). Similarly, the PV panel can emulate the primary frequency response by releasing the retained power reserve. Solar PV can also provide curtailment services when there is a surplus of generated power, although it is not yet common (Gevorgian and O'Neill 2017). In terms of secondary frequency response, the time frames for providing this service by $\mathrm{PV}$ are even shorter than they are for conventional generators (Gevorgian and O'Neill 2016). Figure 10 shows the effectiveness of solar APC after a generation trip event.

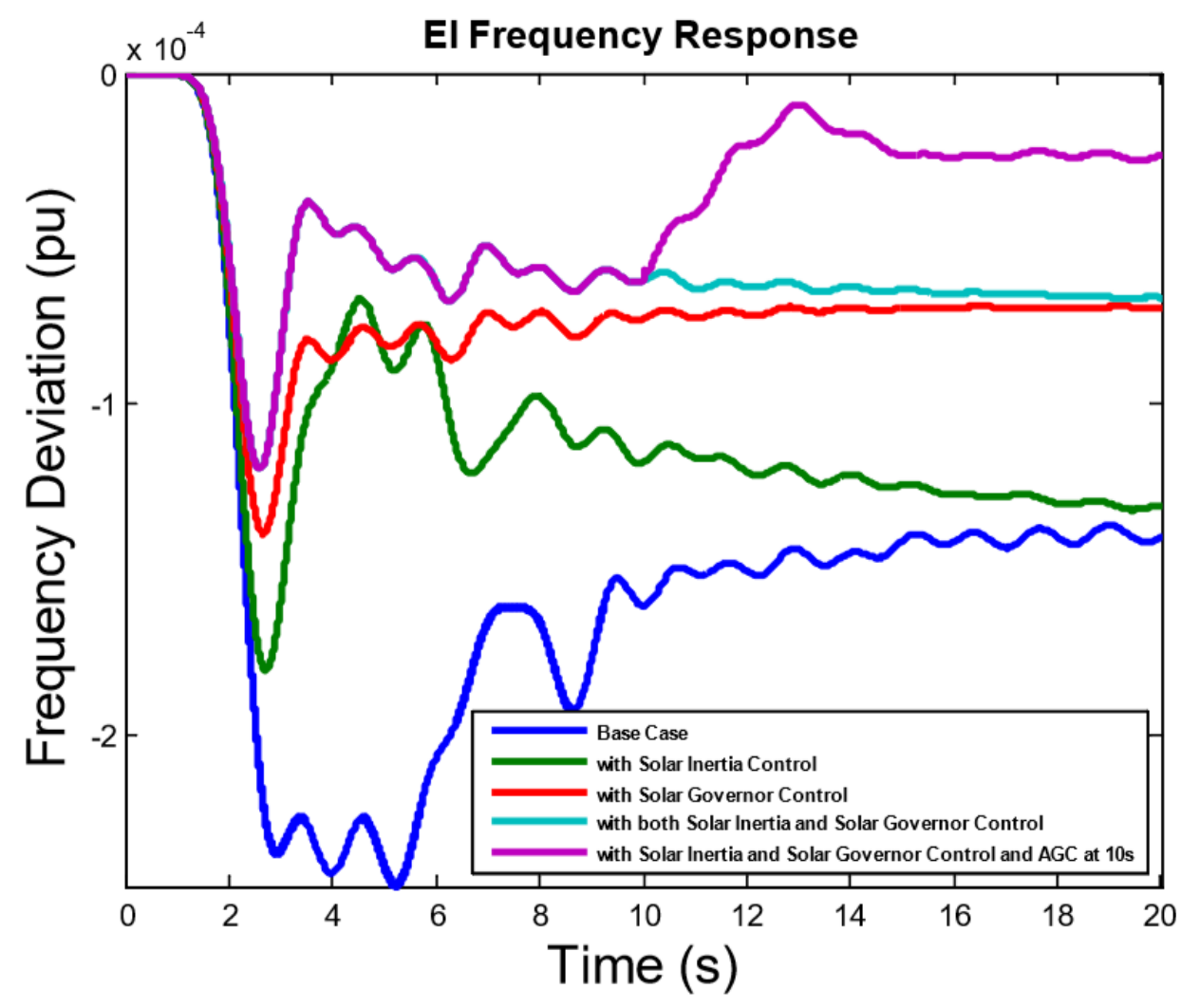

Figure 10. Frequency response of the U.S. Eastern Interconnection (EI) after a generation trip event with different PV generation controls

Adapted from Liu et al. 2013

Enabling large-scale wind and solar APC services can support energy system stability and mitigate variability and uncertainty impacts with increasing renewable penetrations. However, there still are barriers to be considered. For example, to have reserve capabilities to provide inertial and primary frequency response, renewable generators must operate below their full capacities. Key barriers are still being considered and studied in relation to APC for renewables.

Building on the information in this section, a case study of large-scale renewable integration in India is presented the next section. The case study brings together many of the actions and good practices to support large-scale integration of renewables in the bulk power system covered in this section. 


\section{Case Study of Grid Integration in India: Key Actions and Impacts of Large-Scale RE Integration Options}

Under the Greening the Grid initiative, USAID and NREL worked with the Government of India and other stakeholders on a study of grid integration of renewables. ${ }^{12}$ It focused on meeting India's installed RE capacity target of 175 gigawatts (GW) by 2022, which includes an increase in wind capacity to $60 \mathrm{GW}$ and an increase in solar capacity to $100 \mathrm{GW} .^{13}$

The study (Palchak et al. 2017) employed a tailored production cost model to assess operational impacts related to India's RE target as well as actions to support attainment of the target. The modeling effort looked out to 2022 and simulated optimal power generation, including scheduling and dispatch, with total production costs minimized and in the context of certain market, operational and physical constraints. In India, power system operators balance the power system every 15 minutes, thus the same time frame was used for balancing within the model. Based on the analysis, certain actions were recommended that can inform policy and regulatory decisions in India and many align with areas presented in Section 2.

The modeling work showed additional benefits of the 175-GW RE target, including reductions in fuel requirements for coal and natural gas, and carbon dioxide emissions reductions of $21 \%$ compared to no additional RE. It should be noted that though the study showed aggregated benefits under the proposed target, individual coal generators could experience challenges such as revenue losses related to decreased operations as well as higher operation and maintenance costs associated with ramping. Benefits and costs can be assessed within individual countries to determine appropriate courses of action related to RE.

Key actions identified through the study are described in this section. And Text Box 1 outlines the savings and curtailment impacts associated with some of these key actions.

\section{Text Box 1. Summary of India Case Study Findings}

Power system balancing with $100 \mathrm{GW}$ of solar and $60 \mathrm{GW}$ of wind is achievable with minimal integration challenges, bringing benefits of reduced fuel consumption and emissions. Meeting existing regulatory targets for coal flexibility, enlarging geographic and electrical balancing areas, expanding transmission in strategic locations, and planning for future flexibility can enable efficient and reliable operation of the power system now and in the future.

Verbatim text is from NREL (2017).

\footnotetext{
${ }^{12}$ Several technical institutions contributed to the study.

${ }^{13}$ As of 2019, India's power system included approximately $35 \mathrm{GW}$ of wind and $30 \mathrm{GW}$ of solar https://mercomindia.com/indias-solar-capacity-30-gw-milestone/
} 


\subsection{Balancing Area Coordination and Expansion}

Overall, the study found that the power system can be balanced at 15-minute intervals with $100 \mathrm{GW}$ of solar and $60 \mathrm{GW}$ of wind with only minimal RE curtailment of $1.4 \%$ annually, assuming in-state transmission is sufficient. This level of RE could contribute to $22 \%$ of power consumption in India with an instantaneous peak of 54\% nationwide. In three states, RE could meet more than $50 \%$ of energy demand (Figure 11 ).

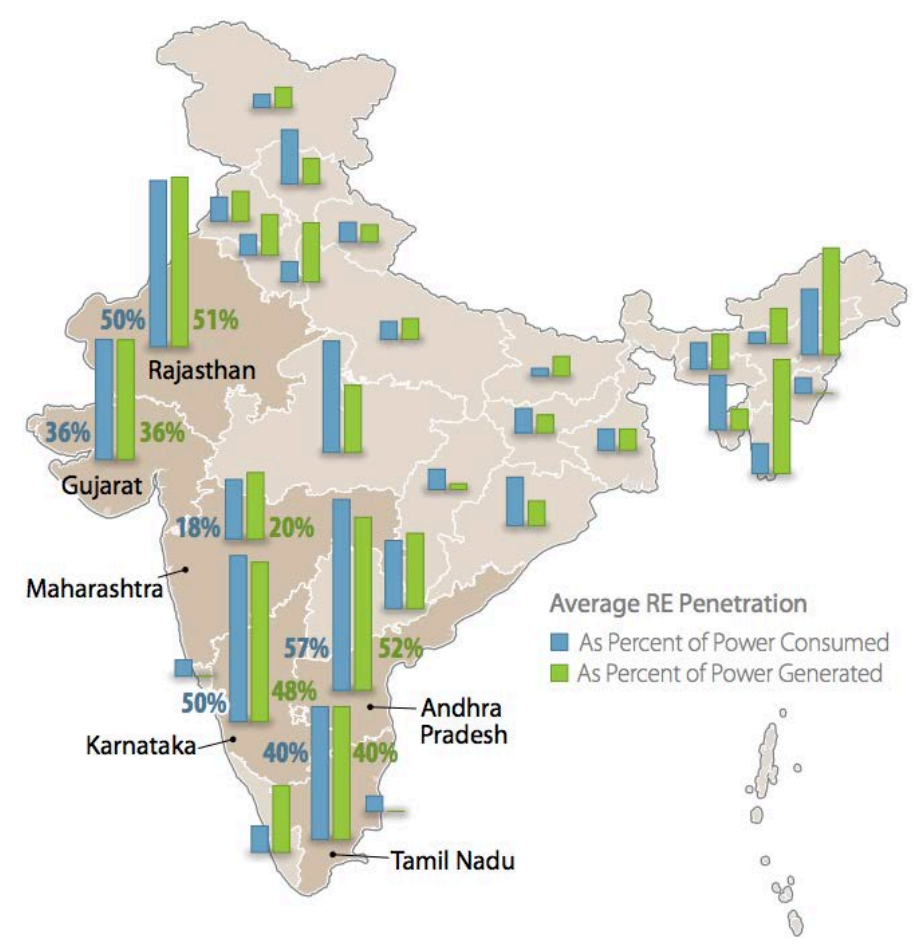

Figure 11. RE used to meet energy demand in India by state

Adapted from NREL 2017

The study also found that to further reduce RE curtailment and cost of power system operation, optimized power scheduling and dispatch could occur at the regional level rather than the state level. In the case of India, and as described in the study, coordination across regions can enable access to least-cost generation, reduce the amount of coal plants operating inefficiently (i.e., not at full capacity), and allow RE to be better placed to provide energy when generation levels are high (by lowering committed coal plant energy production at these times). Though regional coordination could lead to $2.8 \%$ annual operating cost savings and $1.4 \%$ RE curtailment, national coordination could lead to additional benefits, including savings of 3.5\% and total RE curtailment of $0.9 \%$ (NREL 2017). Though these benefits are possible, the operational changes noted are not required to meet India's 160-GW RE goal.

Text Box 2 lists the potential planning and policy actions that can support RE integration, according to the study. 


\section{Text Box 2. Key Actions to Support Balancing Area Coordination and Expansion}

1. Coordinate RE generation and transmission at the state level to ensure sufficient instate transmission.

2. Create regulatory or policy guidelines to support institutionalization of cost-optimized capacity expansion planning. Create and maintain a nationwide model that helps optimize generation and transmission buildouts, which can then be used to inform investment decisions and RE policies.

3. Evaluate options for enhanced coordination of scheduling and dispatch between states and regions.

Verbatim text is from NREL (2017).

\subsection{Flexibility}

The India study noted that coal plant flexibility, in particular lowering minimum plant generation, is a key area to reducing RE curtailment. The reference minimum generation levels for coal plants stand at 55\% with 1.4\% RE curtailment in India, according to the report. As presented in Figure 12, under a coal flexibility sensitivity analysis where this level ranges from $40 \%$ to $70 \%$, RE curtailment could be lower $(0.76 \%)$ or higher $(3.5 \%)$ respectively. The study also explored other scenarios related to minimum generation.

\section{RE INTEGRATION STRATEGIES}

\begin{tabular}{|c|c|c|c|c|c|}
\hline $\begin{array}{l}\text { NORMAL } \\
\text { OPERATIONS }\end{array}$ & The COORDIN & SCHEDULING & \multicolumn{2}{|c|}{ A: COAL PLANT FLEXIBILITY } & \multirow{2}{*}{$\begin{array}{l}\text { LOWER MINIMUM PLANT } \\
\text { GENERATION } \\
\text { (40\% of Capacity) } \\
\text { WITH REGIONAL BALANCING } \\
\text { AREA COORDINATION }\end{array}$} \\
\hline $\begin{array}{l}\text { STATE-LEVEL DISPATCH, } \\
\text { 55\% MINIMUM GENERATION }\end{array}$ & REGIONAL & NATIONAL & $\begin{array}{l}\text { PLANT GENERATION } \\
\text { ( } 40 \% \text { of capacity) }\end{array}$ & $\begin{array}{l}\text { PLANT GENERATION } \\
\text { (70\% of capacity) }\end{array}$ & \\
\hline $\begin{array}{l}230,000 \\
\text { INR Crore } \\
\text { Annual Production Cost }\end{array}$ & $\begin{array}{c}2.8 \% \\
\text { Savings annually } \\
\bar{F}\end{array}$ & $\begin{array}{c}3.5 \% \\
\text { Savings annually } \\
\end{array}$ & $\begin{array}{c}\text { Negligible } \\
\text { Savings annually }\end{array}$ & $\begin{array}{c}0.90 \% \\
\text { Increased cost annually }\end{array}$ & $\begin{array}{c}3.3 \% \\
\text { Savings annually } \\
₹\end{array}$ \\
\hline $\begin{array}{c}1.4 \% \\
\text { Renewable energy } \\
\text { curtailment }\end{array}$ & $\begin{array}{c}1.3 \% \\
\text { Renewable energy } \\
\text { curtailment }\end{array}$ & $\begin{array}{c}\mathbf{0 . 8 9 \%} \\
\text { Renewable energy } \\
\text { curtailment }\end{array}$ & $\begin{array}{c}\mathbf{0 . 7 6} \% \\
\text { Renewable energy } \\
\text { curtailment }\end{array}$ & $\begin{array}{c}3.5 \% \\
\text { Renewable energy } \\
\text { curtailment }\end{array}$ & $\begin{array}{c}\mathbf{0 . 7 3} \% \\
\text { Renewable energy } \\
\text { curtailment }\end{array}$ \\
\hline
\end{tabular}

Figure 12. Actions to enable large-scale RE integration in India

Source: NREL 2017

INR = Indian rupee 
Battery storage was not found in the study to have a significant impact on total cost of generation or RE curtailment (due to efficiency losses). However, it was noted that batteries could be "economically desirable for RE integration for grid services that are outside the scope of the study (e.g., frequency regulation, capacity value, local transmission congestion)." (NREL 2017).

Finally, the study found that retirement of $20 \%$ of installed coal generation (operating at less than $15 \%$ of annual capacity) would not negatively impact the flexibility of the power system. This finding assumed in-state transmission was adequate to bring in new renewables (NREL 2017).

\section{Text Box 3. Key Actions to Support Flexibility}

1. Establish at central and state levels comprehensive regulations regarding flexibility of conventional generators, including minimum generation levels, ramp rates, and minimum up and down times.

2. Develop a new tariff structure that moves away from focusing on energy delivery. Agreements can specify various performance criteria, such as ramping, specified startup or shut-down times, and minimum generation levels, along with notification times and performance objectives that achieve flexibility goals.

3. Revise policy/regulatory-level guidelines to use the full capability of hydro and pumped hydro stations. Suitable incentive mechanisms can encourage operation of hydro and pumped hydro depending upon system requirements.

4. Change requirements so that the scheduling and dispatch of power is based on production costs (merit order dispatch); supplementary software may be required to identify economic scheduling and dispatch that considers the combined effects of conventional and renewable variable costs, transmission congestion and losses, and other factors.

5. Create model power purchase agreements for RE that move away from must-run status and employ alternative approaches to limit financial risks, such as annual caps on curtailed hours.

Verbatim text is from NREL (2017).

\subsection{Grid Integration Studies and Planning}

The study also looked at more ambitious and alternative RE generation mix scenarios that aligned with broader nationally determined contribution goals and offered additional benefits to the system. According to the authors, Indian stakeholders could continue to use tailored capacity expansion and production cost models to support planning over time and in relation to evolving goals. As quality data are a key aspect of these modeling efforts, the authors recommended that regulations be designed to require data inputs from various entities to perform the modeling and develop data-driven plans for large-scale RE integration. 


\subsection{Forecasting}

As highlighted in Section 2, and as a finding of the India study, improved forecasting is a key area to support large-scale RE integration. In the case of India, the study authors recommended all states be equipped with facilities for state-of-the-art load forecasting. States with significant amounts of RE could also be equipped with leading-edge forecasting tools, and the capacity of system operators could be built to develop and customize new forecasting tools over time.

\section{Conclusion}

This report summarizes good practices and interventions to enable renewable bulk power scaleup. The information provided is grounded in lessons globally and a case study for India which provides a more granular look at the key topics covered. Decision-makers and other stakeholders can use the information in the report to support various planning processes, policies, and decisions related to increased deployment of renewable bulk power. 


\section{References}

Barrows, Clayton, Jessica Katz, Jaquelin Cochran, Galen Maclaurin, Mark Christian Marollano, Mary Grace Gabis, Noriel Christopher Reyes, et al. 2018. Greening the Grid: Solar and Wind Grid Integration Study for the Luzon-Visayas System of the Philippines. NREL/TP-6A20-68594. Golden, CO: National Renewable Energy Laboratory.

CAISO (California ISO). 2019. Western EIM Benefits Report Fourth Quarter 2018.

Cochran, Jaquelin, Mackay Miller, Owen Zinaman, Michael Milligan, Doug Arent, and Bryan Palmintier. 2014. Flexibility in 21st Century Power Systems. NREL/TP-6A20-61721. Golden, CO: National Renewable Energy Laboratory.

Cox, Sadie, Owen Zinaman, Karlynn Cory, Kaifeng Xu, Thomas Bowen, Tim Reber, Robin Burton, and Ron Benioff. Forthcoming. Power System Transformation Pathways. Golden, CO: National Renewable Energy Laboratory.

Denholm, Paul, and Jaquelin Cochran. 2015. Balancing Area Coordination: Efficiently Integrating Renewable Energy into the Grid. NREL/FS-6A20-63037. Golden, CO: National Renewable Energy Laboratory.

Ela, Erik. 2013. Variable Renewable Generation Can Provide Balancing Control to the Electric Power System. NREL/FS-5500-57820. Golden, CO: National Renewable Energy Laboratory.

Ela, Erik, Vahan Gevorgian, Paul Fleming, YingChen Zhang, Mohit Singh, Eduard Muljadi, A. Scholbrook, et al. 2014. Active Power Controls from Wind Power: Bridging the Gaps. NREL/TP-5D00-60574. Golden, CO: National Renewable Energy Laboratory.

Gevorgian, Vahan, and Barbara O'Neill. 2017. Demonstration of Active Power Controls by Utility-Scale PV Power Plant in an Island Grid: Preprint. NREL/CP-5D00-67255. Golden, CO: National Renewable Energy Laboratory.

- 2016. Advanced Grid-Friendly Controls Demonstration Project for Utility-Scale PV Power Plants. NREL/TP-5D00-65368. Golden, CO: National Renewable Energy Laboratory.

Hurlbut, David, Ilya Chernyakhovskiy, and Jaquelin Cochran. 2016. Renewable Energy Zones: Delivering Clean Power to Meet Demand. NREL/FS-6A20-65988. Golden, CO: National Renewable Energy Laboratory.

IEA (International Energy Agency), CEM (Clean Energy Ministerial), and 21CPP (21st Century Power Partnership). 2019. Status of Power System Transformation 2019: Power System Flexibility.

Katz, Jessica, and Ilya Chernyakhovskiy. 2016. Grid Integration Studies: Advancing Clean Energy Planning and Deployment. NREL/TP-6A20-66504. Golden, CO: National Renewable Energy Laboratory.

Katz, Jessica, and Jaquelin Cochran. 2015. Integrating Variable Renewable Energy into the Grid: Key Issues. NREL/FS-6A20-63033. Golden, CO: National Renewable Energy Laboratory. 
Knauf, Victoria. 2018. "How Dispatchable Wind Is Becoming a Reality in the US." Accessed May 30, 2019: https://www.greentechmedia.com/articles/read/how-dispatchable-wind-isbecoming-a-reality-in-the-us\#gs.f5z8jo.

Lee, Nathan, Francisco Flores-Espino, and David Hurlbut. 2017. Renewable Energy Zone (REZ) Transmission Planning Process: A Guidebook for Practitioners. NREL/TP-7A40-69043. Golden, CO: National Renewable Energy Laboratory.

Liu, Yong, Jose R. Gracia, Stanton W. Hadley, and Yilu Liu. 2013. Wind/PV Generation for Frequency Regulation and Oscillation Damping in the Eastern Interconnection (EI). ORNL/TM2013/587. Oak Ridge National Laboratory.

Miller, Nicholas W., Monica Shao, Slobodan Pajic, and Robert D’Aquila. 2014. Western Wind and Solar Integration Study Phase 3: Frequency Response and Transient Stability. NREL/SR5D00-62906. Golden, CO: National Renewable Energy Laboratory.

Milligan, Michael, and Jessica Katz. 2016. The Evolution of Power System Planning with High Levels of Variable Renewable Generation. NREL/TP-6A20-63035. Golden, CO: National Renewable Energy Laboratory.

Milligan, Michael, and Brendan Kirby. 2007. Impact of Balancing Areas Size, Obligation Sharing, and Ramping Capability on Wind Integration: Preprint. NREL/CP-500-41809. Golden, CO: National Renewable Energy Laboratory.

Muljadi, Eduard, Vahan Gevorgian, Mohit Singh, and Surya Santoso. 2012. Understanding Inertial and Frequency Response of Wind Power Plants: Preprint. NREL/CP-5500-55335. Golden, CO: National Renewable Energy Laboratory.

Nelson, Jimmy, Saamrat Kasina, John Stevens, Jack Moore, Arne Olson, Mahesh Morjaria, John Smolenski, and Jose Aponte. 2018. Investigating the Economic Value of Flexible Solar Power Plant Operation. Energy+Environmental Economics.

NERC (North American Electric Reliability Corporation). 2014. Integration of Variable Generation Task Force (IVGTF) Final Recommendation Report.

NREL (National Renewable Energy Laboratory). 2017. Greening The Grid: Pathways to Integrate 175 Gigawatts of Renewable Energy into India's Electric Grid. NREL/FS-6A2068745. Golden, CO: National Renewable Energy Laboratory.

Palchak, David, Jaquelin Cochran, Ali Ehlen, Brendan McBennett, Michael Milligan, Ilya Chernyakhovskiy, Ranjit Deshmukh, et al. 2017. Greening the Grid: Pathways to Integrate 175 Gigawatts of Renewable Energy into India's Electric Grid, Vol. I: National Study. Golden, CO: National Renewable Energy Laboratory.

Rothleder, Mark. 2019. Briefing on Western Energy Imbalance Market and Benefits. California Independent System Operator.

http://www.caiso.com/Documents/WesternEnergyImbalanceMarket-BenefitsUpdateMar2019.pdf.

Tian, Tian, and Ilya Chernyakhovskiy. 2016. Forecasting Wind and Solar Generation: Improving System Operations. NREL/FS-6A20-65728. Greening the Grid. 